\title{
Article \\ Severe Reduction of Energy Availability in Controlled Conditions Causes Poor Endurance Performance, Impairs Explosive Power and Affects Hormonal Status in Trained Male Endurance Athletes
}

\author{
Iva Jurov ${ }^{1, *(\mathbb{C},}$, Nicola Keay ${ }^{2}$ and Samo Rauter ${ }^{1}$ (D) \\ 1 Faculty of Sport, University of Ljubljana, 1000 Ljubljana, Slovenia; Samo.Rauter@fsp.uni-lj.si \\ 2 Department of Sport and Exercise Sciences, Durham University, Durham DH1 3LY, UK; \\ nickykeayfrancis@googlemail.com \\ * Correspondence: iva.jurov@gmail.com
}

check for

updates

Citation: Jurov, I.; Keay, N.; Rauter, S. Severe Reduction of Energy

Availability in Controlled Conditions

Causes Poor Endurance Performance, Impairs Explosive Power and Affects Hormonal Status in Trained Male Endurance Athletes. Appl. Sci. 2021, 11, 8618. https://doi.org/10.3390/ app11188618

Academic Editor: Alessandro de Sire

Received: 5 July 2021

Accepted: 10 September 2021

Published: 16 September 2021

Publisher's Note: MDPI stays neutral with regard to jurisdictional claims in published maps and institutional affiliations.

Copyright: (c) 2021 by the authors. Licensee MDPI, Basel, Switzerland. This article is an open access article distributed under the terms and conditions of the Creative Commons Attribution (CC BY) license (https:/ / creativecommons.org/licenses/by/ $4.0 /)$.
Featured Application: Reduced EA in male trained endurance athlete by $50 \%$ results in poor endurance performance, worse explosive power and altered lactate metabolism.

\begin{abstract}
The aim of this study was to severely reduce energy availability (EA) in controlled conditions in trained male endurance athletes to observe any effects on health, performance, and psychological and energy markers. EA was reduced by $50 \%$ over 14 days in athletes by maintaining identical energy intake and increasing exercise energy expenditure. Blood was drawn, performance was measured by three specific tests (endurance, explosive power and agility) and two psychological questionnaires were used. Reduced EA (17.3 $\pm 5.0 \mathrm{kcal} / \mathrm{kg}$ FFM/day) resulted in lower body fat $\%(t(12)=3.36, p=0.006)$, lower power output and relative power output $(t(12)=2.69, p=0.021$ $\mathrm{t}(12)=2.34, p=0.036)$, explosive power was reduced $(\mathrm{t}(12)=6.41, p=0.000)$, lactate metabolism was altered $(p=0.001)$. EA was negatively correlated with haemoglobin and testosterone $(\mathrm{r}=-0.557$, $p=0.30$ and $\mathrm{r}=-0.532, p=0.037)$, anaerobic threshold $(\mathrm{r}=-0.597, p=0.02)$ and respiratory compensation point $(\mathrm{r}=-0.575, p=0.025)$. There were significant differences in Well-being $(\mathrm{t}(12)=4.11$, $p=0.002)$ and the Three Factor Eating Questionnaire $(\mathrm{t}(12)=-2.71, p=0.020)$. This is the first study to demonstrate that endurance performance and explosive power can be affected before detrimental health effects occur in male athletes. Drastic reductions of EA could lead to poor eating behaviours. The two psychological questionnaires seem to be more sensitive to EA changes than blood markers.
\end{abstract}

Keywords: energy availability; performance; endurance athletes; explosive power; lactate metabolism; relative energy deficiency in sport

\section{Introduction}

Low energy availability (LEA) is the aetiological factor for relative energy deficiency in sport (RED-S) [1]. LEA remains an under-researched phenomenon as its measurement represents a high burden for the researcher and the athlete. Most of the identification tools are for females and estimate LEA indirectly with questionnaires, and based on parameters that are in turn indirectly associated with LEA. This is one of the reasons for inconsistent results in finding the cut-off point when LEA has clinical effects. The knowledge we have is also derived from conditions that can overlap with LEA, like eating disorders, overtraining syndrome, high psychological stress in athletes and others [2]. A future goal for easier detection of critical changes in LEA is devising a simple, less burdening tool that will allow detection of changes in energy availability (EA) outside laboratory conditions. Such tools can only be developed by providing direct evidence on association between the real (and not estimated) EA and other possible affected parameters like hormones and athletic performance. In addition, only direct measurement of EA in combination with other 
outcomes can provide the threshold for LEA in men. This remains to be determined [3]. Finally, the theory about the performance effects of LEA is lacking in direct evidence $[1,2,4]$.

We set this research to find direct evidence on how performance, health and mental state are affected when EA is reduced progressively by $50 \%$ in trained well-trained and elite endurance male athletes. The study was designed to measure EA with objective methodology, meaning that EA was determined by using direct tools. The EA was measured in strictly controlled conditions by including athletes without any pre-existing signs of LEA to determine if changes can be found after 14 days.

\section{Materials and Methods}

\subsection{Participants}

Twelve $(\mathrm{N}=12)$ athletes completed the study. The inclusion criteria and selection process is presented in Supplementary File S1. All participants signed an informed consent before commencing all protocols for allowing data to be gathered and analysed anonymously. This research complied with the declaration of Helsinki. National medical ethical approval was acquired before the start of the study (No. 0120-202/2020/5).

Subjects were invited to participate in the study through national cycling and triathlon organizations, professional cycling team's coaches. The information was also disseminated through faculty's laboratory, where the top national endurance athletes regularly perform tests.

Subjects were informed of all procedures and were selected based on inclusion criteria, high motivation and compliance. If they were not motivated enough or did not follow all procedures, they were excluded from further participation and analysis.

\subsection{Study Design}

The study was an intervention cross-sectional controlled laboratory study. Baseline measurements of EA took place over 9 days [5]. Athletes reported energy intake (EI) by completing dietary diaries for 7 consecutive days [6]. At the same time, exercise energy expenditure (EEE) was monitored during all training units. After 1 day of rest, blood was drawn, body composition and resting energy expenditure (REE) were measured, followed by three performance tests for determining basal performance and psychological assessment. These measurements were used as control measurements.

At least 1 month wash-out period was included before commencing the intervention of $50 \%$ EA reduction. The wash-out period was included because this intervention was part of a larger study design and this is how we made sure the athlete returned to the baseline state. All athletes completed all measurements within a 3 month time frame after the baseline measurements. We confirmed that their health and energy status was the same as in baseline stage by repeating vital measurements on day 1 of the $50 \%$ reduction state (Figure 1).

The intervention lasted 14 days (Figure 1). To confirm baseline measurements, blood was drawn, mREE, fat free mass (FFM) were measured on the first day. A Three Factor Eating Questionnaire (TFEQ-R18) and a Wellbeing questionnaire were completed as explained by Jurov et al. [5]. EA was reduced by $50 \%$ in all participants individually by increasing their EEE time with cycling or running. The increase in EEE was chosen for this study design to observe changes in health, performance and well-being at reduced EA by simulating scenarios that are likely among endurance athletes, such as intense training periods lasting 14 days where EEE is drastically increased and EI is identical.

This can happen as athletes do not have time or knowledge to adequately adapt their nutrition. In this study design, their EI remained the same as in baseline, which was controlled by repeating the diary log two times for 3 days in the 14 days (on day 1,2,3, and $8,9,10)$. This enabled a new, lower EA to be achieved. EEE was measured throughout all 14 days. On the 14th day, blood was be drawn, REE and body composition were measured, performance was assessed and TFEQ-R18 and Wellbeing Q were completed. 


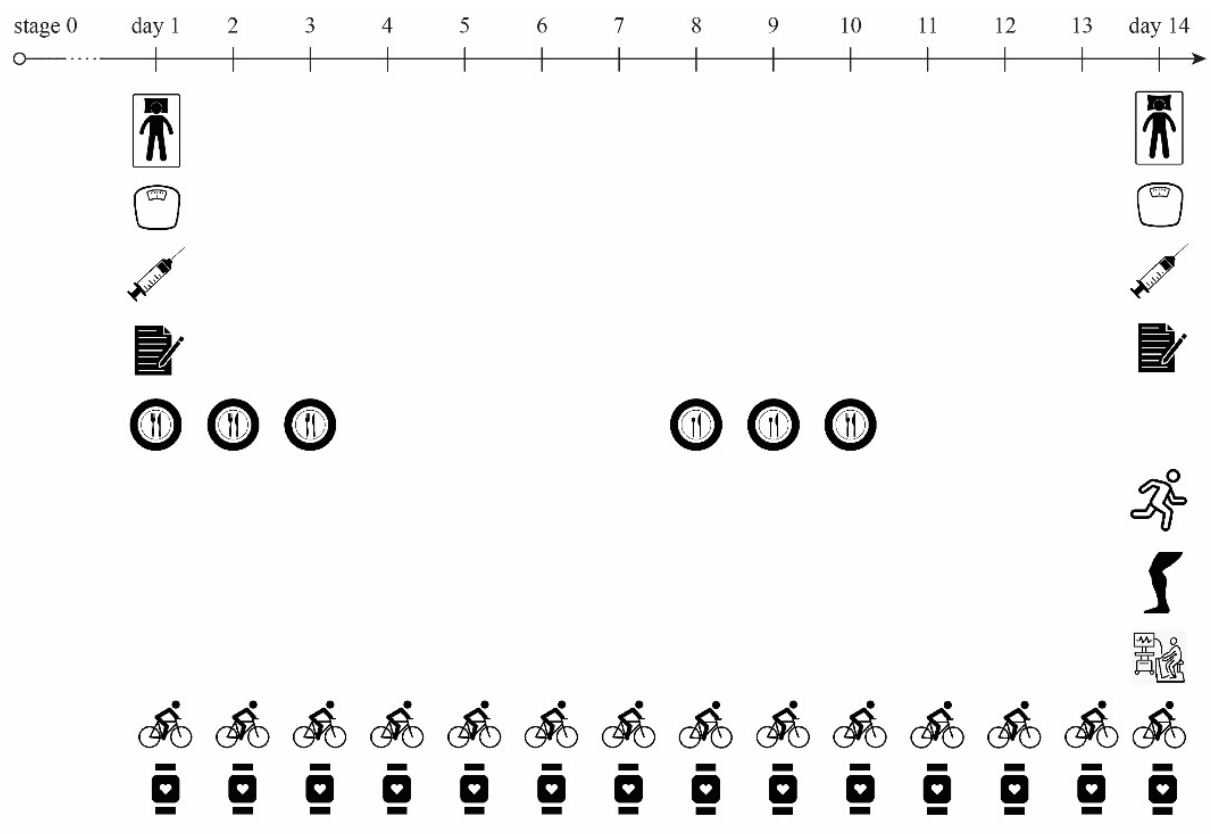

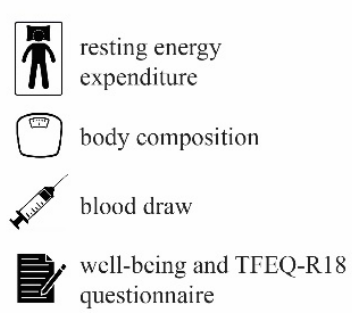

Figure 1. Study design.

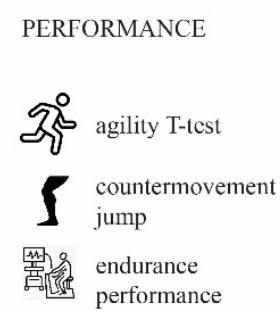

NERGY AVAILABILITY ASSESSMENT

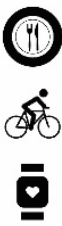

energy intake monitoring

increased exercise energy expenditure

- exercise energy expenditure measurement

\subsection{Procedures}

\subsubsection{Energy Availability Calculation}

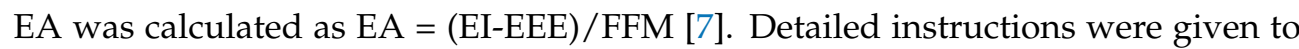
all participants for weighing foods, using measuring tools and providing photographic evidence of everything ingested. Data was analyzed with Foodworks 9 Professional Edition (version 9.0.3973, Xyrix Software, Brisbane, Queensland, Australia). EEE was measured by using wearable heart rate monitors during all exercise sessions (Polar V800, Polar Electro, Kempele, Finland).

To reach the reduced EA by 50\%, EEE was calculated. The new EEE was reached by increasing training time. Subjects exercised every day for a specific time period adjusted to achieve the EEE calculated. They ran or cycled at HR between 70 and $80 \%$ of their maximal HR. EA was identical as in baseline stage and was controlled by diary logs. Dietary recall for controlling EI was done on two times for 3 days since four days, reduction in compliance has been documented [8].

\subsubsection{Performance Testing, Blood Samples, Body Composition and} Psychological Assessment

For performance three tests were used. Complete blood count, ferritin, serum iron (Fe), triiodothyronine (T3), thyroid stimulating hormone (TSH), morning testosterone, fasting insulin, insulin like growth factor 1 (IGF-1) and 9 a.m. cortisol were measured in blood draws. Body composition was assessed using bioelectrical impedance that has been validated against dual-energy $X$-ray absorptiometry [9]. REE was measured with indirect 
calorimetry. The TFEQ-R18 and Wellbeing questionnaires were used. The details of all procedures can be found in Supplementary File S2.

\subsection{Data Analysis}

For statistical analysis, SPSS (version 25.0, IBM SPSS Statistics, Chicago, IL, USA) was used with a significance level of $<0.05$. Paired samples $t$-tests were used to analyse changes in health, performance and metabolic factors in stages 0 and 1 . Descriptive statistics was used to present anthropological factors, age, energy parameters, blood values, performance and psychological evaluation in all stages. Pearson's correlation coefficient was used to find associations between EA and other measured parameters. Minimal sample size needed for this study $(\mathrm{N}=12)$ was calculated with the $\mathrm{G}^{*}$ power 3.1.9.2 software (Heinrich-Heine University, 40213 Düsseldorf, Germany), assuming expected effect size 0.47 as reported in previous studies [10], with type I(a) error $=0.05$ and $30 \%$ dropout of participants.

\section{Results}

There were no statistically significant differences in body mass and FFM before and after the intervention. However, we found significantly lower body fat $\%$ after the 14 days spent in $50 \%$ EA reduction $(\mathrm{t}(12)=3.36, p=0.006, \mathrm{r}=0.71)$ ).

EEE was set to achieve the desired EA 2 (Supplementary File S3). Only one participant failed to finish $50 \%$ EA reduction with determined EEE level-they finished the intervention after 12 days. Since their final EEE was close to calculated EEE for 14 days, they were included in the analysis. Achieved EEE 2 compared to calculated EEE 2 is presented in Supplementary File S3 together with average time and EEE according to training modalities. Achieved EEE was very close to calculated EEE for $50 \%$ EA reduction (Supplementary File S3), mean difference was $8.43 \%$. On average, they cycled $17 \mathrm{~h}$ and $9 \mathrm{~min}$, ran $1 \mathrm{~h}$ and $32 \mathrm{~min}$ and swam $1 \mathrm{~h}$ and $4 \mathrm{~min}$ per week. Average cumulative training time was $2 \mathrm{~h}$ and 50 min per day.

We found no significant differences before and after intervention in mREE or mREE/ pREE. Only $3 / 12$ subjects showed $\mathrm{mREE} / \mathrm{pREE}<0.9$. Mean EA was $17.3 \pm 5.0 \mathrm{kcal} / \mathrm{kg}$ FFM/day. We found no statistical differences in any blood parameters before and after the intervention (Table 1).

Table 1. $t$-test comparing blood parameters before (a) and after (b) $50 \%$ EA reduction.

\begin{tabular}{|c|c|c|c|c|c|c|c|c|c|c|}
\hline & Mean_a & Mean_b & $\begin{array}{l}\text { Mean } \\
\text { Differ- } \\
\text { ence }\end{array}$ & $\begin{array}{l}\text { Std. De- } \\
\text { viation }\end{array}$ & $\begin{array}{l}\text { Std. Error } \\
\text { Mean }\end{array}$ & $\begin{array}{l}95 \% \mathrm{CI} \\
\text { Lower }\end{array}$ & $\begin{array}{l}95 \% \text { CI } \\
\text { Upper }\end{array}$ & $\mathbf{t}$ & df & $\begin{array}{c}\text { Sig. } \\
\text { (2-Tailed) }\end{array}$ \\
\hline Haemoglobin $(g / L)$ & 146.4 & 143.92 & 2.50 & 4.81 & 1.39 & -0.56 & 5.56 & 1.80 & 11 & 0.100 \\
\hline S-Iron $(\mu \mathrm{mol} / \mathrm{L})$ & 22.94 & 22.62 & 0.32 & 8.79 & 2.54 & -5.26 & 5.91 & 0.13 & 11 & 0.900 \\
\hline S-TSH (mIU/L) & 2.28 & 2.16 & 0.12 & 0.55 & 0.16 & -0.23 & 0.47 & 0.74 & 11 & 0.475 \\
\hline S-T3 (pmol/L) & 4.78 & 4.60 & 0.19 & 0.40 & 0.12 & -0.07 & 0.44 & 1.63 & 11 & 0.132 \\
\hline $\begin{array}{c}\text { S-Testosterone } \\
\text { (nmol/L) }\end{array}$ & 19.22 & 18.86 & 0.35 & 5.46 & 1.58 & -3.11 & 3.82 & 0.22 & 11 & 0.827 \\
\hline S-cortisol (nmol/L) & 408.80 & 408.81 & -0.01 & 92.47 & 26.69 & -58.76 & 58.74 & 0.00 & 11 & 1.000 \\
\hline S-ferritin $(\mu \mathrm{g} / \mathrm{L})$ & 140.40 & 138.81 & 1.59 & 21.01 & 6.07 & -11.76 & 14.94 & 0.26 & 11 & 0.798 \\
\hline Insulin (mE/L) & 2.80 & 2.85 & -0.05 & 1.98 & 0.57 & -1.31 & 1.21 & -0.09 & 11 & 0.932 \\
\hline IGF-1 $(\mu \mathrm{g} / \mathrm{L})$ & 187.75 & 170.83 & 16.92 & 28.60 & 8.25 & -1.25 & 35.09 & 2.05 & 11 & $0.065^{*}$ \\
\hline IGF-1 SD & -0.085 & -0.277 & 0.192 & 0.811 & 0.234 & -0.324 & 0.707 & .819 & 11 & 0.430 \\
\hline
\end{tabular}

* Significance set at $p<0.05$ (TSH = thyroid stimulating hormone, T3 = triiodothyronine, IGF-1 = insulin-like growth factor 1).

There were individual differences in results. Looking at critical values, two participants reached haemoglobin levels under the normal reference range, one reached too high cortisol and ferritin levels. In one subject, testosterone dropped under the normal range value. We found that haemoglobin and testosterone were correlated with EA. Other blood parameters were not correlated to EA (Table 2). 
Table 2. Blood parameters correlations to EA at the end of the intervention.

\begin{tabular}{|c|c|c|c|c|c|c|c|c|c|c|c|}
\hline & & Haemoglobin_b & $\begin{array}{c}\text { S- } \\
\text { Iron_b }\end{array}$ & $\begin{array}{c}\text { S- } \\
\text { TSH_b }\end{array}$ & $\begin{array}{l}\text { S- } \\
\text { T3_b }\end{array}$ & $\begin{array}{c}\text { S- } \\
\text { Testosterone_b }\end{array}$ & $\begin{array}{c}\text { S- } \\
\text { Cortisol_b }\end{array}$ & $\begin{array}{c}\text { S- } \\
\text { Ferritin_b }\end{array}$ & Insulin_b & IGF-1_b & $\begin{array}{l}\text { IGF-1 } \\
\text { SD_b }\end{array}$ \\
\hline \multirow{3}{*}{$\begin{array}{l}\text { EA_2 } \\
\text { real }\end{array}$} & $\mathbf{r}$ & $0.557^{*}$ & 0.242 & 0.307 & 0.048 & $0.532 *$ & -0.384 & 0.094 & 0.318 & -0.335 & 0.056 \\
\hline & $p$ & 0.030 * & 0.224 & 0.166 & 0.441 & $0.037^{*}$ & 0.109 & 0.386 & 0.157 & 0.144 & 0.431 \\
\hline & $\mathbf{N}$ & 12 & 12 & 12 & 12 & 12 & 12 & 12 & 12 & 12 & 12 \\
\hline
\end{tabular}

* Statistical significance set at $p<0.05$ (1-tailed).

On average, participants had significantly lower power output (PO) $(\mathrm{M}=387.5$, $\mathrm{SE}=24.2)$ compared to baseline values $(\mathrm{M}=404.2, \mathrm{SE}=36.8), \mathrm{t}(12)=2.69, p=0.021, \mathrm{r}=0.63$. Accordingly, their relative power output $(\mathrm{RPO})(\mathrm{M}=5.44, \mathrm{SE}=0.34)$ was significantly lower than before intervention $(\mathrm{M}=5.62, \mathrm{SE}=0.43), \mathrm{t}(12)=2.34, p=0.036, \mathrm{r}=0.57$ (Figure 1).

We also observed significant differences in maximal lactate values ([La $]_{\max }$ ), lactate values obtained $5 \mathrm{~min}$ after the end of the incremental test $\left([\mathrm{La}]_{5 \mathrm{~min}}\right)$ and countermovement jump height (Table 3).

Table 3. Paired samples test of other performance related parameters before and after $50 \%$ EA reduction.

\begin{tabular}{|c|c|c|c|c|c|c|c|c|}
\hline & $\begin{array}{c}\text { Mean } \\
\text { Difference }\end{array}$ & SD & $\begin{array}{l}\text { Std. Error } \\
\text { Mean }\end{array}$ & $\begin{array}{l}95 \% \mathrm{CI} \\
\text { Lower }\end{array}$ & $\begin{array}{l}95 \% \text { CI } \\
\text { Upper }\end{array}$ & $\mathbf{t}$ & df & $\begin{array}{c}\text { Sig. } \\
\text { (2-Tailed) }\end{array}$ \\
\hline $\begin{array}{c}\mathrm{VO}_{2 \max } \\
(\mathrm{mL} / \mathrm{min} / \mathrm{kg})\end{array}$ & -0.86 & 6.29 & 1.82 & -4.86 & 3.14 & -0.47 & 11 & 0.646 \\
\hline AT $(\mathrm{mL} / \mathrm{min} / \mathrm{kg})$ & -2.94 & 6.06 & 1.75 & -6.79 & 0.91 & -1.68 & 11 & 0.121 \\
\hline $\mathrm{RC}(\mathrm{mL} / \mathrm{min} / \mathrm{kg})$ & -3.93 & 8.31 & 2.40 & -9.20 & 1.35 & -1.64 & 11 & 0.130 \\
\hline$[\mathrm{La}]_{\max }(\mathrm{mmol} / \mathrm{L})$ & 3.38 & 2.63 & 0.76 & 1.71 & 5.05 & 4.45 & 11 & $0.001 *$ \\
\hline$[\mathrm{La}]_{5 \min }(\mathrm{mmol} / \mathrm{L})$ & 2.89 & 2.25 & 0.65 & 1.46 & 4.32 & 4.44 & 11 & $0.001 *$ \\
\hline$t$-test (s) & 0.09 & 0.32 & 0.09 & -0.11 & 0.30 & 1.008 & 11 & 0.335 \\
\hline CMJ (m) & 0.035 & 0.019 & 0.005 & 0.023 & 0.047 & 6.416 & 11 & $0.000 *$ \\
\hline
\end{tabular}

* Statistical significance set at $p<0.05 .\left(\mathrm{VO}_{2 \max }=\right.$ maximal oxygen consumption, $\mathrm{PO}=$ peak power output, $\mathrm{RPO}=$ relative power output, $\mathrm{AT}=$ anaerobic threshold, $\mathrm{RC}=$ respiratory compensation point, $[\mathrm{La}]_{\max }=$ lactate concentration at the end of the test, $[\mathrm{La}]_{5 \mathrm{~min}}=$ lactate concentration $5 \mathrm{~min}$ after the end of the test, CMJ = countermovement jump).

There were significant correlations in anaerobic threshold (AT) $(\mathrm{r}=-0.597, p=0.02)$ and respiratory compensation point $(\mathrm{RC})(\mathrm{r}=-0.575, p=0.025)$ with EA. The difference in agility $t$-test was not big enough to be statistically significant. However, agility $t$-test $(\mathrm{M}=6.39 \pm 0.42)$ was correlated to EA before and after the intervention $(\mathrm{r}=0.534, p=0.037)$. Countermovement jump was not associated with EA $(r=-0.346, p=0.135)$ (Table 4$)$.

Table 4. Correlations of energy parameters with performance.

\begin{tabular}{|c|c|c|c|c|c|c|c|c|c|c|}
\hline & & $\begin{array}{l}{[\mathrm{La}]_{5 \min }} \\
(\mathrm{mmol} / \mathrm{L})\end{array}$ & $\begin{array}{c}{[\mathrm{La}]_{\max }} \\
(\mathrm{mmol} / \mathrm{L})\end{array}$ & $t$-Test (s) & $\mathrm{CMJ}(\mathrm{m})$ & $\begin{array}{c}\mathrm{VO}_{2 \max } \\
(\mathrm{mL} / \mathrm{min} / \mathrm{kg})\end{array}$ & PO (W) & $\begin{array}{c}\text { RPO } \\
\text { (W/kg) }\end{array}$ & $\begin{array}{c}\mathrm{AT} \\
(\mathrm{mL} / \mathrm{min} / \mathrm{kg})\end{array}$ & $\begin{array}{c}\mathrm{RC} \\
(\mathrm{mL} / \mathrm{min} / \mathrm{kg})\end{array}$ \\
\hline \multirow{3}{*}{ mREE/pREE } & $\mathrm{r}$ & -0.134 & -0.409 & -0.149 & -0.088 & $0.518^{*}$ & 0.016 & 0.090 & 0.431 & 0.348 \\
\hline & $p$ & 0.339 & 0.094 & 0.322 & 0.393 & 0.042 & 0.480 & 0.391 & 0.081 & 0.134 \\
\hline & $\mathrm{N}$ & 12 & 12 & 12 & 12 & 12 & 12 & 12 & 12 & 12 \\
\hline \multirow{3}{*}{$\begin{array}{c}\text { mREE } \\
\text { (kcal/day) }\end{array}$} & $\mathrm{r}$ & -0.066 & -0.370 & -0.218 & -0.143 & 0.425 & 0.010 & -0.030 & 0.343 & 0.243 \\
\hline & $p$ & 0.419 & 0.118 & 0.248 & 0.329 & 0.084 & 0.487 & 0.464 & 0.138 & 0.223 \\
\hline & $\mathrm{N}$ & 12 & 12 & 12 & 12 & 12 & 12 & 12 & 12 & 12 \\
\hline \multirow{3}{*}{$\begin{array}{c}\text { EA } \\
\text { achieved }\end{array}$} & $\mathrm{r}$ & 0.058 & 0.039 & 0.534 * & -0.346 & -0.457 & -0.001 & -0.171 & -0.597 * & -0.575 * \\
\hline & $p$ & 0.430 & 0.452 & 0.037 & 0.135 & 0.067 & 0.499 & 0.297 & 0.020 & 0.025 \\
\hline & $\mathrm{N}$ & 12 & 12 & 12 & 12 & 12 & 12 & 12 & 12 & 12 \\
\hline
\end{tabular}

${ }^{*}$ Statistical significance set at $p<0.05$ (1-tailed) $(\mathrm{mREE}=$ measured resting energy expenditure, $\mathrm{pREE}=$ predicted resting energy expenditure, $\mathrm{EA}=$ energy availability, $\mathrm{VO}_{2 \max }=$ maximal oxygen consumption, $\mathrm{PO}=$ peak power output, $\mathrm{RPO}=$ relative power output, $\mathrm{AT}=$ anaerobic threshold, $\mathrm{RC}=$ respiratory compensation point, $[\mathrm{La}]_{\max }=$ lactate concentration at the end of the test, $[\mathrm{La}]_{5 \mathrm{~min}}=$ lactate concentration $5 \mathrm{~min}$ after the end of the test, $\mathrm{CMJ}=$ countermovement jump).

There were significant differences in wellbeing $(\mathrm{t}(12)=4.11, p=0.002, \mathrm{r}=0.78)$ and TFEQ $(\mathrm{t}(12)=-2.71, p=0.020, \mathrm{r}=0.63 .8 / 12(66 \%)$ of subjects showed critical 
CR before intervention and 10/12 (83.3\%) after (CR $\geq 13)$. Absolute values were not significantly different.

No correlations were found to EA. When asked about subjective feelings in this stage, any differences or comments, only one subject failed to report any problems. Other personal observations are shown in Supplementary File S3.

\section{Discussion}

Drastically reducing EA by increasing EEE in male trained endurance athletes for 50\% in 14 days results in significant reduction in body fat, lower testosterone and haemoglobin, together with reduction in endurance performance and explosive power. It can also result in compromised immunity and it could lead to reduced IGF-1. This intervention did not result in any changes in REE. Psychological assessment was successful in detecting reduced EA and reduction by $50 \%$ represents a danger for athlete's eating behaviours.

\subsection{Changes in Blood Values}

We observed a tendency for lower IGF-1 $(\mathrm{t}(12)=2.049, p=0.065, \mathrm{r}=0.53)$. This is in accordance with review by Elliot-Sale et al. [11] that concluded IGF-1 tends to be lower in low EA state in male and female athletes. The review looked into three papers that analysed male athletes. None of them actually measured EA: Geesman et al. [12] observed a 54-h ultra-endurance event and energy balance, Hagman et al. [13] designed a study by measuring body composition and using questionnaires and Maestu et al. [14] observed bodybuilders. They did not measure EA directly, they estimated energy restriction from self-reported training logs and intermittently measured 3-days dietary intake in seven athletes and seven controls. We can speculate that a longer duration or a bigger sample size in our study would lead to significantly different IGF-values. We suggest further research is needed to actually prove low EA is associated with IGF-1.

Lowering EA for $25 \%$ in the same sample (unpublished data, baseline published in [5]) resulted in lower haemoglobin values $(t(12)=2.652, p=0.022)$, but there was no correlation to EA. It seems that in more severe conditions, we were able to show the correlation of EA and haemoglobin. Also, the lower the EA, the lower the testosterone. We failed to find any differences in testosterone function as detected by morning erections. It might suggest that lowered EA must persist for a longer time frame or EA must be lower in order to change functional effect of testosterone. It is not yet clear how LEA affects hypothalamicpituitary-gonadal axis in men [11]. Studies so far have not been consistent. Conclusions that lower EA might be associated with lower testosterone were made according to seven studies. Five of them did not measure EA at all [15-19] and two papers looking into testosterone and EA [10,20] did not use objective methodology for EA. Heikura et al. [10] used the most accurate approach to detect EA from the studies mentioned. They concluded that questionnaires provide better estimation of energy for health than measuring EA. In contrast to that study, our research measured EEE instead of estimating it. What is more, their study was designed as low EA being $<30 \mathrm{kcal} / \mathrm{kg}$ FFM/day, which is an unconfirmed data derived from studies in females. We can certainly confirm that direct measurement of EA is challenging. However, this is the only way to provide direct link between hormonal changes and EA. To the best of our knowledge our paper provides novel finding that reducing EA is associated with lower testosterone. Objective measurement in our sample proved that suboptimal energy state can result in negative health consequences.

Finally, although we cannot present direct evidence of energy deficiency causing compromised immunity, we can report that $3 / 12(25 \%)$ cases experienced an upper respiratory infection that resulted in inability to train.

\subsection{Performance}

We found poorer endurance performance as detected by PO and RPO and altered lactate metabolism (shown as lower lactate values at the end and 5 min after the test). The lower the EA, the worse were endurance markers AT and RC. All these parameters 
are crucial for endurance performance and indicate that athletes performed worse after the intervention. We can conclude that lowering EA by $50 \%$ results in poorer endurance performance. In addition to changes in endurance performance, explosive power was reduced. Also, although $t$-test was positively associated with EA, which was due to individual differences from baseline measurements, participants showed slower performance (although insignificant, $p=0.335$ ) at the end of 50\% EA reduction. To conclude, we provide evidence that endurance and explosive power are affected as early as in 14 days and prior to significant hormonal changes.

\subsection{Energy Conservation}

This intervention did not result in any significant changes in energy conservation as detected by mREE/pREE. In addition, mREE/pREE was not associated with EA. However, greater energy conservation was associated with poorer $\mathrm{VO}_{2 \max }$. This is consistent with findings in female competitive cyclists where reduced endurance performance was shown to be associated with lower mREE/pREE [21]. For any conclusions in male athletes, more research is needed. Since our participants reported that they probably could not endure a longer duration of this intervention, we suggest further reducing EA in similar study design would be a logical new step for determining any direct links between EA and energy conservation. There are, however, ethical considerations to this intervention.

\subsection{Psychological Changes}

Psychological evaluation tools were useful in detecting EA changes. Athletes had poorer eating behaviours and worse wellbeing. Since eating behaviours did not change when EA was lowered by $25 \%$ in the same research setting (in preparation for publication), we speculate that a drastic reduction by $50 \%$ presents a danger for athletes' eating behaviours. Based on these results when EA needs to be lowered for body composition changes, we suggest moderate reductions up to $25 \%$ are more suitable for prevention of disordered eating behaviour. In addition to the validated tools used, subjective reports indicate that the majority couldn't have endured this intervention for more than just a few days after the predetermined 14-days intervention (Supplementary File S3). Our findings add to our knowledge that regular monitoring of mental state is essential in athletes that have EA changes, which usually happen in periodisation process before competition phase.

\subsection{The Threshold for Low Energy Availability}

Changes in performance, psychological assessment and associations with blood values in our sample suggest that the threshold for LEA might be higher than suggested by Koehler et al. (15 kcal/kg FFM/day) [22]. Our research was aimed to individually lower EA based on baseline values and the athletes reached the mean EA $17.3 \pm 5.0 \mathrm{kcal} / \mathrm{kg}$ FFM/day. We cannot determine the threshold with this study design, but we can report that a value of 15 might be too low, since our sample showed detriments that are part of RED-S as described by the IOC consensus group in 14 days already [1]. Indeed, LEA can occur more slowly and the transition from optimal EA to LEA can be subtle, thus causing different, maybe smaller effects on health, performance and wellbeing. The difficulty of recognising clinical effects is also a reason why LEA can last a long time before being detected, certainly longer than 14 days. Since our findings suggest such EA could not last for a much longer time than 14 days without further impairment in wellbeing, we believe the cut-off value might be above the proposed $15 \mathrm{kcal} / \mathrm{kg}$ FFM/day.

\subsection{Limitations}

The authors would like to acknowledge that although all participants were trained endurance athletes, some of them fall into the well-trained and also elite group according to De Pauw et al. [23]. Finding sufficiently large sample size of only elite athletes is a challenge in such a research setting. This is why we used athletes from all three performance groups. To our knowledge, this is the biggest sample in a controlled setting for measuring EA 
in trained endurance male athletes and can thus provide some relevant conclusions for scientists, athletes, their coaches and other sports practitioners. Only this approach can enable further exploration of LEA effects on the male hypothalamic-pituitary-gonadal axis (Logue et al. 2020) and performance consequences.

\section{Conclusions}

In summary, we provide direct evidence that reduced EA in male trained endurance athlete by $50 \%$ results in poor endurance performance, worse explosive power and altered lactate metabolism. It negatively affects wellbeing and eating behaviours. The TFEQ and Wellbeing questionnaire are useful tools for detection of changes and seem to be more sensitive than blood changes. Drastic reductions of EA could lead to poor eating behaviours and we suggest EA should be lowered by no more than $25 \%$ in order to avoid potential eating disorders. This is the first study providing direct evidence that EA is correlated with testosterone, meaning that EA was measured and not estimated. It is also the first to prove that performance can be affected before health detrimental effects occur. This implies the necessity for further research in EA in males. The findings also suggest that the threshold for LEA in men is above $15 \mathrm{kcal} / \mathrm{kg}$ FFM/day. The practical application of this study is that male athletes should aim for optimal EA when striving for results. Drastic changes in EA have harmful effect on performance as early as in 14 days, which should be of great interest for coaches in endurance disciplines when considering body mass optimisation in athletes. Finally, whether mREE/pREE could be used in future as a surrogate marker for suboptimal EA needs more evidence.

Supplementary Materials: The following are available online at https:/ /www.mdpi.com/article/10 .3390/app11188618/s1, Supplementary File S1: Table S1: Inclusion criteria for participants, Figure S1: Flowchart of enrolment, Supplementary File S2: Table S2: Well-being subjective questionnaire with scoring system, Supplementary File S3: Table S3: Subjective assessment of 50\% EA reduction from all 12 participants, Figure S2: Differences in EEE before intervention and during the 50\% EA reduction state, Figure S3: The calculated EEE for 50\% EA reduction compared to the achieved EEE for each of the 12 subjects, Figure S4: Time and EEE divided into training modalities as measured in 50\% EA reduction intervention.

Author Contributions: Conceptualization, I.J., N.K., S.R., methodology I.J.; N.K.; S.R., formal analysis I.J., investigation I.J.; resources, I.J.; data curation, I.J.; writing-original draft preparation, I.J.; writing-review and editing, I.J., N.K., S.R.; supervision S.R.; funding acquisition I.J. All authors have read and agreed to the published version of the manuscript.

Funding: This research was funded by Slovenian Research Agency grant number P5-0147. The funder had no role in study design, data collection and analysis, decision to publish, or preparation of the manuscript.

Institutional Review Board Statement: The study was conducted according to the guidelines of the Declaration of Helsinki. National medical ethical approval was acquired before the start of the study (No. 0120-202/2020/5).

Informed Consent Statement: Informed consent was obtained from all subjects involved in the study.

Data Availability Statement: Additional Data are available upon reasonable request.

Conflicts of Interest: The authors declare no conflict of interest.

\section{References}

1. Mountjoy, M.; Sundgot-Borgen, J.; Burke, L.; Carter, S.; Constantini, N.; Lebrun, C.; Meyer, N.; Sherman, R.; Steffen, K.; Budgett, R.; et al. The IOC consensus statement: Beyond the Female Athlete Triad-Relative Energy Deficiency in Sport (RED-S). Br. J. Sports Med. 2014, 48, 491-497. [CrossRef]

2. Mountjoy, M.; Sundgot-Borgen, J.; Burke, L.; Ackerman, K.E.; Blauwet, C.; Constantini, N.; Lebrun, C.; Lundy, B.; Melin, A.; Meyer, N.; et al. International Olympic Committee (IOC) Consensus Statement on Relative Energy Deficiency in Sport (RED-S): 2018 Update. Int. J. Sport Nutr. Exerc. Metab. 2018, 28, 316-331. [CrossRef] 
3. Burke, L.M.; Lundy, B.; Fahrenholtz, I.L.; Melin, A.K. Pitfalls of Conducting and Interpreting Estimates of Energy Availability in Free-Living Athletes. Int. J. Sport Nutr. Exerc. Metab. 2018, 28, 350-363. [CrossRef] [PubMed]

4. Logue, D.M.; Madigan, S.M.; Melin, A.; Delahunt, E.; Heinen, M.; Donnell, S.M.; Corish, C.A. Low Energy Availability in Athletes 2020: An Updated Narrative Review of Prevalence, Risk, Within-Day Energy Balance, Knowledge, and Impact on Sports Performance. Nutrients 2020, 12, 835. [CrossRef]

5. Jurov, I.; Keay, N.; Hadzic, V. Relationship between energy availability, energy conservation and cognitive restraint with performance measures in male endurance athletes. J. Int. Soc. Sports Nutr. 2021, 18, 24. [CrossRef] [PubMed]

6. Capling, L.; Beck, K.; Gifford, J.; Slater, G.; Flood, V.; O'Connor, H.; Capling, L.; Beck, K.L.; Gifford, J.A.; Slater, G.; et al. Validity of Dietary Assessment in Athletes: A Systematic Review. Nutrients 2017, 9, 1313. [CrossRef] [PubMed]

7. Loucks, A.B.; Thuma, J.R. Luteinizing hormone pulsatility is disrupted at a threshold of energy availability in regularly menstruating women. J. Clin. Endocrinol. Metab. 2003, 88, 297-311. [CrossRef]

8. Magkos, F.; Yannakoulia, M. Methodology of dietary assessment in athletes: Concepts and pitfalls. Curr. Opin. Clin. Nutr. Metab. Care 2003, 6, 539-549. [CrossRef]

9. Syed-Abdul, M.M.; Soni, D.S.; Barnes, J.T.; Wagganer, J.D. Comparative analysis of BIA, IBC and DXA for determining body fat in American Football players. J. Sports Med. Phys. Fit. 2021, 61, 687-692. [CrossRef]

10. Heikura, I.A.; Stellingwerff, T.; Bergland, D.; Mero, A.A.; Burke, L.M. Low Energy Availability Is Difficult to Assess but Outcomes Have Large Impact on Bone Injury Rates in Elite Distance Athletes. Int. J. Sport Nutr. Exerc. Metab. 2018, 28, 403-411. [CrossRef]

11. Elliott-Sale, K.J.; Tenforde, A.S.; Parziale, A.L.; Holtzman, B.; Ackerman, K.E. Endocrine Effects of Relative Energy Deficiency in Sport. Int. J. Sport Nutr. Exerc. Metab. 2018, 28, 335-349. [CrossRef]

12. Geesmann, B.; Gibbs, J.C.; Mester, J.; Koehler, K. Association Between Energy Balance and Metabolic Hormone Suppression During Ultra-Endurance Exercise. Int. J. Sports Physiol. Perform. 2017, 12, 984-989. [CrossRef]

13. Hagmar, M.; Berglund, B.; Brismar, K.; Hirschberg, A.L. Body Composition and Endocrine Profile of Male Olympic Athletes Striving for Leanness. Clin. J. Sport Med. 2013, 23, 197-201. [CrossRef]

14. Mäestu, J.; Eliakim, A.; Jürimäe, J.; Valter, I.; Jürimäe, T. Anabolic and Catabolic Hormones and Energy Balance of the Male Bodybuilders During the Preparation for the Competition. J. Strength Cond. Res. 2010, 24, 1074-1081. [CrossRef]

15. Chan, J.L.; Heist, K.; DePaoli, A.M.; Veldhuis, J.D.; Mantzoros, C.S. The role of falling leptin levels in the neuroendocrine and metabolic adaptation to short-term starvation in healthy men. J. Clin. Investig. 2003, 111, 1409-1421. [CrossRef] [PubMed]

16. Berg, U.; Enqvist, J.K.; Mattsson, C.M.; Carlsson-Skwirut, C.; Sundberg, C.J.; Ekblom, B.; Bang, P. Lack of sex differences in the IGF-IGFBP response to ultra endurance exercise. Scand. J. Med. Sci. Sports 2008, 18, 706-714. [CrossRef] [PubMed]

17. McColl, E.M.; Wheeler, G.D.; Gomes, P.; Bhambhani, Y.; Cumming, D.C. The effects of acute exercise on pulsatile LH release in high-mileage male runners. Clin. Endocrinol. 1989, 31, 617-621. [CrossRef] [PubMed]

18. Hackney, A.C.; Sinning, W.E.; Bruot, B.C. Reproductive hormonal profiles of endurance-trained and untrained males. Med. Sci. Sports Exerc. 1988, 20, 60-65. [CrossRef] [PubMed]

19. Hackney, A.C.; Fahrner, C.L.; Gulledge, T.P. Basal reproductive hormonal profiles are altered in endurance trained men. J. Sports Med. Phys. Fit. 1998, 38, 138-141.

20. Hooper, D.R.; Kraemer, W.J.; Saenz, C.; Schill, K.E.; Focht, B.C.; Volek, J.S.; Maresh, C.M. The presence of symptoms of testosterone deficiency in the exercise-hypogonadal male condition and the role of nutrition. Eur. J. Appl. Physiol. 2017, 117, 1349-1357. [CrossRef]

21. Jurov, I.; Hadžić, V.; Rauter, S. Markers of Energy Metabolism Affect Lactate Metabolism and Aerobic Performance in Competitive Female Cyclists. Appl. Sci. 2020, 10, 7563. [CrossRef]

22. Koehler, K.; Hoerner, N.R.; Gibbs, J.C.; Zinner, C.; Braun, H.; De Souza, M.J.; Schaenzer, W. Low energy availability in exercising men is associated with reduced leptin and insulin but not with changes in other metabolic hormones. J. Sports Sci. 2016, 34, 1921-1929. [CrossRef] [PubMed]

23. De Pauw, K.; Roelands, B.; Cheung, S.S.; de Geus, B.; Rietjens, G.; Meeusen, R. Guidelines to classify subject groups in sport-science research. Int. J. Sports Physiol. Perform. 2013, 8, 111-122. [CrossRef] [PubMed] 